\title{
Management strategies in urban green spaces: Models based on an introduced exotic pet turtle
}

\author{
Teillac-Deschamps Pauline ${ }^{\mathrm{a}, *}$, Lorrilliere Romain ${ }^{\mathrm{b}}$, Servais Véronique ${ }^{\mathrm{e}}$, Delmas Virginie ${ }^{\mathrm{a}}$, \\ Antoine Cadi a,f , Prevot-Julliard Anne-Caroline ${ }^{\mathrm{a}, \mathrm{c}, \mathrm{d}}$ \\ ${ }^{a}$ Univ Paris-Sud, Laboratoire Ecologie, Systématique et Evolution, CNRS, AgroParis Tech, UMR8079, Orsay Cedex F-91405, France \\ ${ }^{\mathrm{b}}$ UMR 7204 MNHN-CNRS-UPMC, Conservation des espèces, restauration et suivi des populations, Muséum National d'Histoire Naturelle, 55 rue Buffon, Paris F-75005, France \\ ${ }^{\mathrm{C}}$ Institut des Sciences de la Communication du CNRS (ISCC), 27 rue Damesme, Paris F-75013, France \\ ${ }^{\mathrm{d}}$ Université de Cergy-Pontoise, F-91405 Cergy-Pontoise, France \\ e Institut des Sciences humaines et sociales, Laboratoire d'Anthropologie sociale et culturelle, Université de Liège, Belgium \\ ${ }^{\mathrm{f}}$ Fondation Nicolas Hulot pour la Nature et l'Homme, 6 rue de l'Est, Boulogne Billancourt F-92100, France
}

\section{A R T I C L E I N F O}

\section{Article history:}

Received 1 August 2008

Received in revised form 27 April 2009

Accepted 5 May 2009

Available online $\mathrm{xxxx}$

\section{Keywords:}

Conservation

Management

Communication

Education

Urban

Nature perception

Exotic pets

\begin{abstract}
A B S T R A C T
A number of recent authors have emphasised the increasing disconnection from conservation issues among urban dwellers. In a global increase of urbanisation, this disconnect can have an impact on conservation practices. Here, we discuss how managers of public green spaces can contribute to global biodiversity preservation, through combined efforts to preserve local biodiversity and educate the public about conservation issues. We compared several management strategies, including those that mixed direct action on local biodiversity with public education and those that did not. Two kinds of one-way communication were considered as well as a two-way communication process, which take into account different perceptions and practices of nature. We based our model on the introduction of the red-eared slider turtle, Trachemys scripta elegans, into urban French freshwater ecosystems.

We found that direct actions only had a limited, short term effect on the abundance of feral turtles in green spaces and had no effect on the level of public concern about environmental questions. We also showed that a mix of different communication strategies improved people's awareness and altered behaviour with respect to introduced species issues. Finally, we showed the importance of a two-way communication that takes into account the diversity of personal perceptions and practices as regards nature in urban areas in order to achieve sustainable conservation measures and objectives.
\end{abstract}

() 2009 Elsevier Ltd. All rights reserved.

\section{Introduction}

In a world with a growing urban population, conservation biology faces new challenges beyond the traditional difficulties associated with preserving endangered species and habitat. Growing urbanisation is a threat to biodiversity when it causes the destruction of wild areas and/or refugee zones for endangered species (Zhao et al., 2006). However, urban biodiversity cannot be simply ignored in conservation practices, at least because cities accommodate a majority of the global human population (Sanderson et al., 2002), more or less concerned with conservation goals (Miller and Hobbs, 2002).

Among the specific challenges in urban biodiversity preservation efforts is the potentially high proportion of exotic species among urban fauna and flora (e.g., Lonsdale, 1999; McKinney, 2002). Based on the results of several studies that demonstrated

\footnotetext{
* Corresponding author. Tel.: +33 1407953 97; fax: +33 169155696 .

E-mail address: pauline.teillac@u-psud.fr (T.-D. Pauline).
}

the deleterious impact of exotic species on local biodiversity throughout the world (e.g., Jones et al., 2008), urban managers are encouraged to remove these species as soon as detected. However, the decision to remove exotic species may face opposition from the public which possess social and cultural perceptions of animals, plants and nature ${ }^{1}$ in general, that may be different from scientific views (Minteer and Collins, 2005b).

The goal of conservation biologists is to preserve the functional state of 'nature'. However, what constitutes 'nature' may vary according to the sociological and geographical background (Buijs et al., 2006). Considering restoration objectives (Palmer et al., 1997), it refers mainly to extant wildlife (e.g., Sanderson et al., 2008; Seddon et al., 2007) or to former native species that have become extirpated (Donlan et al., 2005), while in other cases (Kaplan and Kaplan, 1989; Ulrich, 1984) it may include domesticated and

\footnotetext{
${ }^{1}$ In the paper, we used the term "nature" when referring to the people perception and "biodiversity" when referring to conservation biologists and managers perceptions.
} 
ornamental species. Fischer and Young (2007) underlined that many different conceptions of what nature is coexist (e.g., idyllic Arcadian landscape, functional biological system) and are linked to people's attitudes towards biodiversity management. Species and habitats can be defined as "important" for any reasons including for conservation, for people's own personal enjoyment, as economically important (e.g., fishing), as symbols of identity or just that they are nice to see (Stewart, 2006). These mental constructs must be considered when defining conservation objectives in order to obtain sustainable results (Bremner and Park, 2007; Colding et al., 2006; Minteer and Collins, 2005a).

Acknowledging the diversity of social and cultural perceptions is even more important when considering introduced species that are former pets or ornamental plants. As such, these species are well known to city dwellers, who may regard them highly. Indeed, Lindemann-Matthies (2005) showed that children are first attracted by exotic animal and plant species because they are familiar with them, but are capable of changing their perception after having been informed about other species. These issues highlight the complex and multi-disciplinary problem that faces conservation managers, who have only finite resources to accomplish their goals.

To integrate the various conceptions of nature in a common knowledge, the communication between involved stakeholders is the key process. The term "communication" is used to refer to a message (content) transmitted from a sender to a receiver (Shannon and Weaver, 1949). However, the manner in which the message is delivered and received (relation) has been progressively considered as being at least as important as the content. As identified by Ruesch and Bateson (1951) and later popularized by Watzlawick et al. (1967), every communication is formed of two parts: the message (content) and the manner in which the message is delivered and received (relation). The content simply what is said, and represent the rational aspect of communication. The relation concerns how information is conveyed and it represents the emotional part of communication. The aspect how the message should be understood - is it advice, or a request? - defines the relationship between sender and receiver. Communication tools focus on the message (content) delivered when the relationship between senders and receivers is well established (e.g., in teaching). The message can be complex and contain an immense amount of information. This communication is the common tool used by experts and scientists in conservation biology, which assume that the transmission of an established knowledge will increase public's commitment in favour of biodiversity conservation (e.g., Brewer, 2002). However, this classical description of communication from a sender to a receiver is restrictive. On conservation issues, for instance, numerous reasons can prevent urban dwellers to engage themselves in conservation practices, such as economic, aesthetic and political. This one-way communication process is also very restrictive in comparison with a two-way dialogue between communicative partners. The roles of sender and receiver may be inverted, provided that each partner accepts the legitimacy of the others (see Nespor, 2000; Pandey, 2003). Several authors underlined the importance of such cross-communication to achieve sustainable management practices (Siebert et al., 2008).

In this paper we studied the managers' dilemma in their contribution to biodiversity preservation, through local urban attitudes towards nature with the particular case of introduced exotic pets. Among the vast number of managers' objectives (e.g., providing recreational opportunities or ecosystem services for residents), we focused on two main goals as regards conservation issues (see Tan, 2006): (i) preserving local biodiversity in their managed area, and (ii) educating urban dwellers about nature and conservation. We built a process-based model for the management of feral exotic pets in urban green spaces that incorporates both ecological considerations and human behaviours. First, we compared different management strategies based on combinations of one-way communication techniques and direct action - in this case, removal of the introduced species. Second, we modelled the acknowledgement of the various perceptions of nature among involved stakeholders in a two-way communication process, integrating a positive feeling people might have towards feral pets. We considered two different decision-making processes: (i) the decision of any particular owner to get rid of his pet, and (ii) the decision by a manager to allocate resources to direct management alone (turtle removal), or to combine this approach with communication strategies. We compared the consequences of these management strategies on the dynamics of both exotic pet abundance in the managed area, and people's concern about environmental issues. Our case study focused on the red-eared slider turtle, Trachemys scripta elegans. This species is one of the most introduced exotic pet into urban French freshwater ecosystems and was a very common exotic pet in the 1980s. Release events started in the early 90's and still take place despite importation ban in 1997. The biology and ecology of this species is well known in its home range, what represents valuable information about its needs in the introduced area.

\section{Socio-ecological system}

Feral exotic pets are subject to a complex social system that involves many interconnected stakeholders (Fig. 1): a pet is first bought by private owners. Later, if those owners decide that they do not want to keep their pet, but do not want it euthanized, they must choose between taking it to a shelter and releasing it into the nearby environment. Because slider turtles were fashionable in the 1980s and 1990s, a very large part of the French population owned one. In our study, we assumed that turtle private owners represent a random sample from the urban population, independent of personal interest and conservation concerns. Urban dwellers represent the first stakeholder in our model. Today, the sale of imported T. scripta elegans is illegal as their importation is forbidden in the European Union since 1997. However, French bred turtles can still be sold and owners can still consider releasing their pets. Other related species (such as Trachemys scripta scripta) are sold and released as well.

Urban dwellers: They are one of the major stakeholders (Fig. 1) (i) because a sample of them is responsible for the release of exotic pets, and (ii) because they are ultimately the target of education efforts by conservation managers. Urban dwellers form a gradient from those who never go to green spaces to those who wish to maintain contact with nature in their everyday lives.

Managers: Here the managers represent professionals who are in charge with a given area (urban green space, local reserve, etc.) and decide what to do with the national public funds they obtain.

We focused on two complementary methods managers have to preserve local biodiversity: (i) acting directly on feral exotic pets and capture them, or (ii) interacting with urban dwellers (Fig. 1). When interacting with people, managers mostly perform a classical one-way communication process: they behave as senders and the urban dwellers remain in a receiver position. The more widespread tool for this kind of communication is a transfer of information and recommendations through exhibitions in public parks or outdoor education for example. This communication approach, which we have termed "proximate communication", assumes that receivers are willing to gather, accept and implement information on their own. Proximate communication can inform people (thanks to scientific papers, popularized literature, newsletters, etc.) of the potential threat to biodiversity posed by feral exotic 


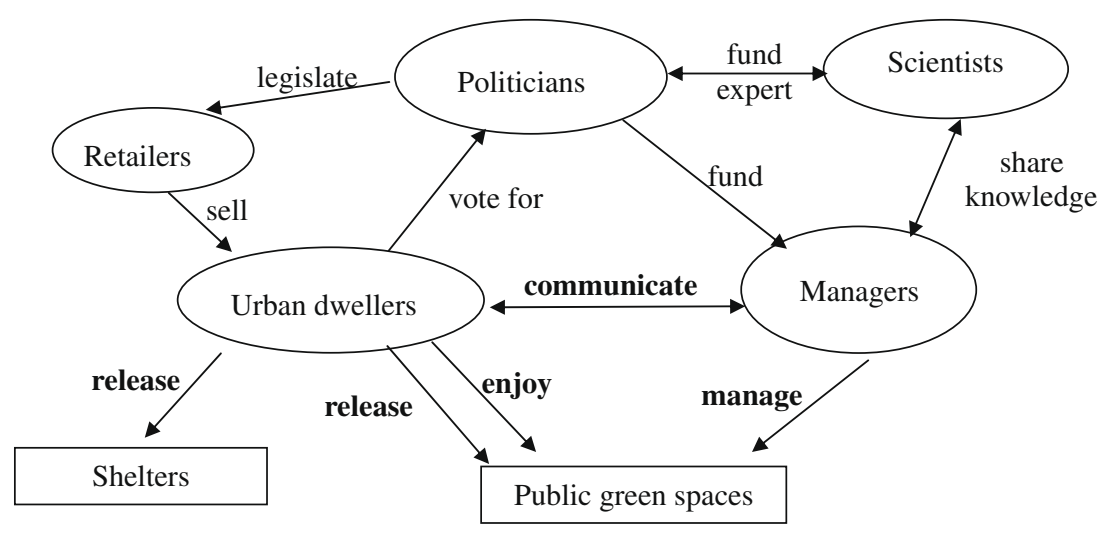

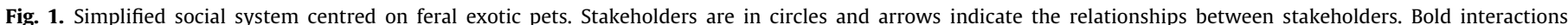
represent those addressed here.

pets when released into local ecosystems. Those who are already environmentally concerned are good receivers for such environmental messages, and will listen to and probably apply the messages communicated to them. But what about people who are not environmentally concerned?

Successfully encouraging people to support biodiversity preservation is a matter of a much wider communication. This other kind of one-way communication is built to be shaped to target preexisting public perceptions (e.g., Kidd and Kidd, 1996). According to the variability of mental constructions, a broad range of communication tools is adopted, such as outdoor education (Nespor, 2000), personal contacts with nature (Roskaft et al., 2003), ecological art (Simon, 2006), movies and citizen science programs (Evans et al., 2005; Roskaft et al., 2003). We termed this communication "general communication". The goal of this communication is to get in touch with much more people than what could be done by the single scientific-based message of the proximate communication (Gonzalez del Solar and Marone, 2001).

In their effort to foster a positive attitude toward biodiversity conservation among the public (reconnecting people with nature nearby, see Miller, 2006), managers and scientists could even go further than simple one-way communication techniques, whether proximate or general, where they are only senders of the messages. Indeed, to be sustainable, the interactions between stakeholders (here managers and urban dwellers) must involve the integration of a variety of perceptions of nature even if they are directly opposite one to another (Minteer and Collins, 2005a,b). In order to reach the establishment of basic ecological principles as "common knowledge" (see Buijs et al., 2006; Higgs, 2006), managers must also be receivers and integrate the various perceptions of nature in the conservation processes. In our case, we took into account the fact that a part of urban dwellers - those who are not interested in environmental issues - may be attracted to green spaces because of the presence of feral exotic species. Once attracted to these green spaces, they would inevitably encounter other facets of nature present in these areas, and could come away with a greater receptivity to environmental communication. This attraction to exotic species could thus become a path for sensitising perception and raising environmental awareness.

\section{Methods}

\subsection{Studied species}

From the 1970s to the 1990s, red-eared slider turtles, Trachemys scripta elegans, became very popular as pets in Europe because of their small size, their simple husbandry requirements and their affordability. Unsuspecting turtle owners were rarely prepared to maintain large adults (up to $30 \mathrm{~cm}$ carapace length) in captivity for up to 50 years. As a result, over time adult turtles have been released into ponds in many places. Slider turtles are now present in freshwater ecosystems in many developed countries (e.g., Arvy and Servan, 1998; Chen and Lue, 1998; de Roa and Roig, 1997; Luiselli et al., 1997; Martinez-Silvestre et al., 2003), with high densities in urban wetlands (Pascal et al., 2006).

The slider turtle's native range is the East part of North America, (Gibbons, 1990), where they live in freshwater ecosystems. Their reproductive period extends from March to August in temperate regions and incubation success depends on local climate conditions (Cadi et al., 2004), leading to an absence of effective reproduction in large areas where they have been released (e.g., Northern parts of Europe).

\subsection{Multi-agent system (MAS): turtlepolicy}

We modelled Trachemys scripta elegans population density with an individual-based spatially explicit multi-agent system (MAS, Bousquet and Le Page, 2004). Using such an individual-based approach, we can model the dynamics of a group as a consequence of local interactions between its individual members. Employing MASs allowed us to model the effects of different stakeholders' behaviours (here, managers, private owners/urban dwellers and turtles, see later) on the dynamics of two outputs: the abundance of turtles and proportion of urban dwellers aware of environmental issues.

\subsubsection{Spatial-temporal structure of turtlepolicy}

- Space: We modelled the space were the turtles move as a single pond of 9 ha (i.e., 9 cells) surrounded by grasslands. This space comprised a grid of hexagonal cells corresponding to 1 ha each.

- Temporal structure: We considered a time step of 1 month, based on the biology of red-eared slider turtles. This time step means that all the behaviours implemented in the model are monthly divided and the turtles start new actions every month. However, some of the behaviours were defined on an annual time scale.

\subsubsection{Involved stakeholders in turtlepolicy}

We implemented three different stakeholders in turtlepolicy: feral turtles, private owners/urban dwellers (we assumed that private owners are a representative sample of urban dwellers) and managers (see Fig. 1). We modelled the various demographic behaviours of the turtles and the main behaviour of private owners 
that can interfere with the dynamic of the turtles' population, i.e., the releasing process. We formalised hypothetical steps of this releasing process after having conducted informal interviews and meetings with a range of individuals, including public policy makers, scientists in biology, managers, retailers and urban dwellers. The various behaviours of the managers were stated as scenarios. In every scenario, the manager's strategy is constant over time. We compared the simulations first performed with variability in the various parameters of the model and, in a second time, with fixed realistic values (see Table 1 for the range of variability and the fixed values of the parameters).

- Feral turtles: Feral turtles present in the model were all adults because individuals released in nature are mostly adults (personal observation). Every month, virtual feral turtles could move within the pond.

Survival: We imposed a single major annual mortality event. Every January, the survival rate (Table 1 ) imposed the rate of adult turtles culled.

Reproduction: Our study first included a total failure of the incubation process in the simulations, as Delmas (2006) stated that despite mating events there is no successful reproduction in the northern part of Europe for Trachemys scripta elegans. Then, we included a variable reproductive success to reflect empirical situations such as in Southern Europe and Asia.

The only variable parameter of the reproductive process in our model was the egg survival. We chose to model a maximum reproduction situation where all the turtle mate from April to June at least once a year, and all the females find a suitable place to lay eggs. The life cycle from eggs to adults was modelled as follows:

The egg survival was randomised around the literature value (i.e., 10\%, Gibbons, 1990 - see Table 1). After two months, eggs become hatchlings with a annual survival rate equal to 0.5 (Gibbons, 1990). After one year hatchlings become juveniles with a survival rate equal to 0.8 (Gibbons, 1990). Finally juveniles become adults following a Gaussian distribution: $m=6, \sigma=1$ for males; $m=10, \sigma=2$ for females (Gibbons, 1990).

- Private owners/urban dwellers: In turtlepolicy, every private owner had only one turtle. At the beginning of each year a random number, corresponding to the number of owners who decided to release their turtle, was submitted to the releasingdecision process (see Fig. 2), which led to a certain number of turtles being released each year. We first prevented any new sales of turtles: the amount of private owners was decided at the beginning of each simulation and decreased progressively. In a second time, we allowed a various amount of turtles to be sold every year (e.g., the 1997 importation ban did not prevent from selling turtles born in European farms). The pool of private owners was thus varying in each simulation and depended on both the number of new owners and the number of ex-owners who have released their turtle.

Conceptual model of the release process: We modelled the turtle release process as a dichotomous multi-step decision-making process (Fig. 2) with individuals categorised, based on four criteria: (1) environmentally concerned, or not; (2) aware of the potential ecological damages caused by introduced species, or not; (3) concerned about the welfare of the turtle, or not; and (4) aware of the existence of shelters, or not.

Following this model, disposed turtles are deposited in nature in four out of six routes. The percentage contributed by each route depends on their respective rates as defined at the beginning of each simulation (see Fig. 2).

- Managers: We considered a single manager in the system for the total area. The management decisions were modelled so to reflect a policy of fewest turtles (first goal), and to educate more people about environmental issues (second goal). The manager had access to three different tools: turtle capture, proximate communication and general communication. The manager had a finite amount of money available annually for all tools choosing for use during the year, arbitrary provided each January.

Table 1

Range and fixed value for each parameter of the model.

\begin{tabular}{|c|c|c|c|c|}
\hline Name & Abbreviation & Definition & Range & Fixed value \\
\hline Adult survival & SurvAd & Survival of adult turtles & {$[0.85 ; 0.95]$} & 0.90 (Gibbons, 1990) \\
\hline Initial number & InitNbTut & Number of turtles in the pond at the beginning of the simulations & {$[10 ; 60]$} & 30 \\
\hline Amount of money & SumManag & $\begin{array}{l}\text { Amount of money available for management every year calculated as equivalent to a } \\
\text { fixed number of traps during a given period }\end{array}$ & $\begin{array}{l}{[0 ; 4]} \\
\text { months }\end{array}$ & 2 \\
\hline Capture probability & ProbaCapt & Probability for a turtle to be caught when there is a trap in the same cell & {$[0.1 ; 0.9]$} & $\begin{array}{l}0.5 \text { (unpublished } \\
\text { data) }\end{array}$ \\
\hline \multirow{6}{*}{$\begin{array}{l}\text { Parameters of the } \\
\text { releasing process }\end{array}$} & a & Rate of people environmentally concerned & {$[0 ; 1]$} & 0.4 \\
\hline & $\mathrm{b}$ & $\begin{array}{l}\text { Rate of people informed about introduced species issues among environmental } \\
\text { friendly people }\end{array}$ & {$[0 ; 1]$} & 0.9 \\
\hline & $\mathrm{b}^{\prime}$ & $\begin{array}{l}\text { Rate of people informed about introduced species issues among "new" } \\
\text { environmental friendly people }\end{array}$ & {$[0 ; 1]$} & 0.5 \\
\hline & c & $\begin{array}{l}\text { Rate of people who knows the existence of shelters, among people environmentally } \\
\text { concerned and informed about introduced species issues }\end{array}$ & {$[0 ; 1]$} & 0.5 \\
\hline & $\mathrm{d}$ & $\begin{array}{l}\text { Rate of people who cares about the well-being of the turtles among people not } \\
\text { environmentally concerned }\end{array}$ & {$[0 ; 1]$} & 0.5 \\
\hline & e & $\begin{array}{l}\text { Rate of people who knows the existence of shelters among people not } \\
\text { environmentally concerned and who does not care about the well-being of the turtles }\end{array}$ & {$[0 ; 1]$} & 0.5 \\
\hline $\begin{array}{l}\text { Communication } \\
\text { efficiency }\end{array}$ & EffCom & EffCom is a logistic regression with $K=1$, and $r=($ Sqrt(SumManag) $) * X$ & $\begin{array}{l}X \text { in } \\
{[0.01 ; 0.2]}\end{array}$ & $X=0.05$ \\
\hline $\begin{array}{l}\text { Efficiency of the general } \\
\text { communication }\end{array}$ & EffG & EffG $=$ EffCom & & \\
\hline $\begin{array}{l}\text { Efficiency of the } \\
\text { proximate } \\
\text { communication }\end{array}$ & EffP & $\mathrm{EffP}=u *$ EffCom & $u$ in $[0.5 ; 4]$ & $u=2$ \\
\hline Egg survival & EggSurv & $\begin{array}{l}\text { During the incubation process (that lasts two months) egg survival is randomly } \\
\text { chosen in the following range }\end{array}$ & {$[0.0005 ; 0.2]$} & $\begin{array}{l}\text { Egg survival }=0.10 \\
\text { Gibbons }(1990)\end{array}$ \\
\hline $\begin{array}{l}\text { Amount of turtles sold } \\
\text { every year }\end{array}$ & NbSold & Increases the amount of private owners who can enter the releasing process & {$[0 ; 20]$} & 0 \\
\hline
\end{tabular}




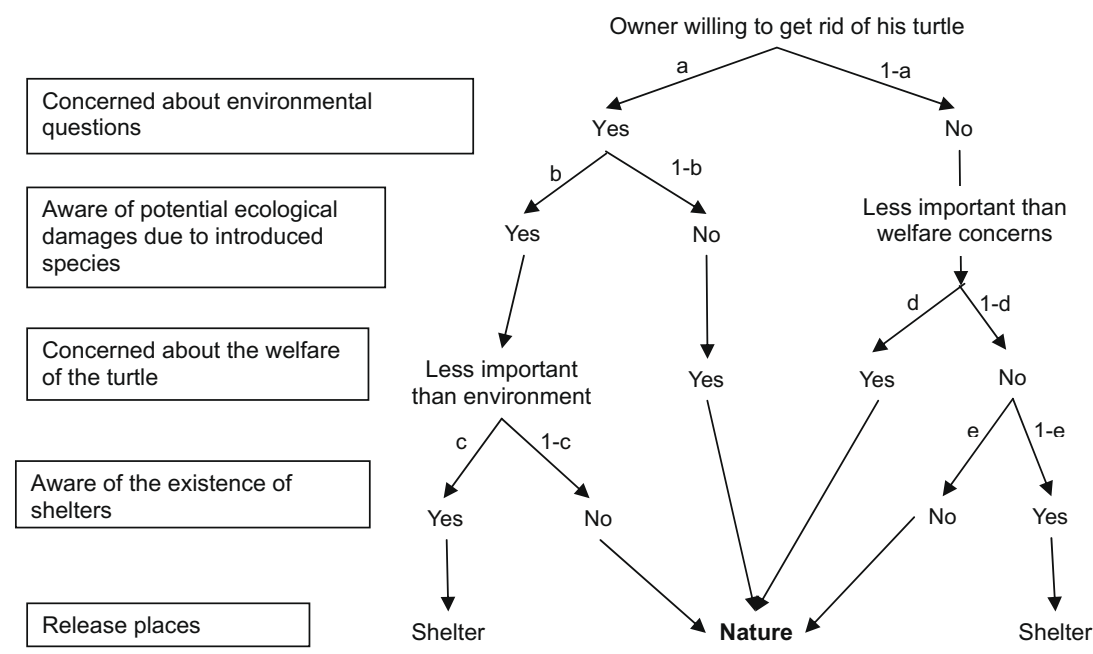

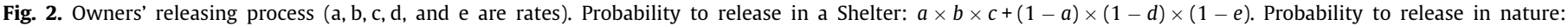
$a \times b \times(1-c)+a \times(1-b)+(1-a) \times d+(1-a) \times(1-d) \times e$.

Capture process: We modelled the capture process as random, based on randomised turtle movements. The turtles present in the same cell as a trap are caught and placed in a shelter with a variable probability ProbaCapt (see Table 1).

Communication processes: When the manager performed general communication, the proportion of people sensitive to environmental issues increased (rate " $a$ "; Fig. 2). When a manager performed proximate communication, the level of information possessed by those who were already environmentally concerned changed (rate "b"; Fig. 2). We imposed the constraint that, among people who become sensitive to environmental issues, the proportion of people informed of the potential ecological damage caused by introduced species (rate " $b^{\prime \prime}$; Fig. 2) differed from that of people environmentally concerned for a longer time (rate " $b$ "; Fig. 2). The values of the parameters are detailed in Table 1.

We modelled the efficiency of the communication processes (EffCom) as a logistic regression: $E_{\mathrm{t}+1}=E_{\mathrm{t}} \exp \left[\mathrm{r}\left(1-E_{\mathrm{t}} / K\right)\right]$ (see Shannon, 1948).

$K=1$, since the maximum efficiency of communication is when everyone is touched by the communication process.

$r=\operatorname{Sqrt}($ 'SumCom') $* X$. SumCom is the amount of money the manager actually uses in the communication process. It depends on the modelled scenario (see later). $X$ is a proportionality parameter, variable in our first analysis and later fixed for the analysis including reproduction (see Table 1 ).

We modelled the efficiency of proximate (EffP) and general (EffG) communication as a function of this communication efficiency: $\mathrm{EffG}=\mathrm{EffCom}$ and $\mathrm{EffP}=u *$ EffCom (see Table 1 ).

\subsection{Tested scenarios}

We first conducted a regression tree analysis (De'ath and Fabricius, 2000) in order to test the sensitivity of our model to the parameters. Regression trees were calculated using R 2.7.2 ( $R$ Development Core Team, 2007) and the RPART package (Therneau and Atkinson, 1997).

Then we tested the consequences of four different scenarios, on both the number of feral turtles and the proportion of people sensitised to environmental issues (i.e., the global proportion of people environmentally concerned and aware of the potential damages of introduced species). Each management scenario was modelled using the same strategy for 20 years. For each scenario, we per- formed 300 simulations. The results are the mean Monte-Carlo estimates of the 300 simulations for each scenario. All the parameters of the model remain constant (to the randomly chosen value at the beginning of each simulation) during the 20 years simulations, except $a$ and $b: a$ increased with general communication and $b$ increased with proximate communication.

The initial amount of turtle owners was fixed (InitNbOwners $=100$ ), as well as the annual proportion of owners entering the releasing process (20\%).

\subsubsection{Scenario 1: capture only}

In this scenario, the manager allots the entire amount of money he has each year (i.e., 'SumManag') to capture strategies. During a trapping session, the manager randomly places a given number of traps in the pond at the beginning of a month and removes them at the end. The number of capture sessions per year is given by the value of 'SumManag'.

\subsubsection{Scenario 2: capture, with proximate communication}

In this scenario, the manager allots his resources to captures and proximate communication. He had thus fewer capture sessions than in scenario 1 ('SumManag'/2) and allots the remaining money ('SumManag'/2) to proximate communication.

\subsubsection{Scenario 3: capture, with general communication}

In this scenario, the manager allots his resources to capture and general communication. He had thus the same amount of capture occasions than in scenario 2 ('SumManag'/2) but allots the remaining money ('SumManag'/2) to general communication.

3.3.4. Scenario 4: capture, with proximate and general communication

In this scenario, the manager allots his resources to capture, proximate and general communications. He has thus fewer capture occasions ('SumManag'/3) than the others scenarios and allots half of the remaining money ('SumManag'/3) to proximate communication and the other half of the remaining resources ('SumManag'/3) to general communication.

\subsubsection{Two different contexts}

We examined the four scenarios in two contexts:

(i) Indifference of the urban dwellers to the presence of turtles in green spaces. 
Table 2

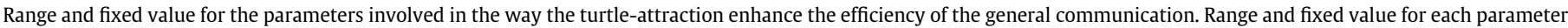
of the model.

\begin{tabular}{|c|c|c|c|c|}
\hline Name & Abbreviation & Definition & Range & $\begin{array}{l}\text { Fixed } \\
\text { value }\end{array}$ \\
\hline $\begin{array}{l}\text { Optimal number of } \\
\text { turtles }\end{array}$ & MeanAtt & $\begin{array}{l}\text { Optimal amount of turtles that increases the efficiency of the general } \\
\text { communication }\end{array}$ & $\begin{array}{l}{[1 ; 50] \text { turtles for a }} \\
1 \text { ha pond }\end{array}$ & 20 \\
\hline $\begin{array}{l}\text { Efficiency of the } \\
\text { attractive effect }\end{array}$ & EffAtt & $\begin{array}{l}\text { We implemented variability in the way the attractive effect enhance the } \\
\text { efficiency of the general communication }\end{array}$ & {$[1 ; 4]$} & 2 \\
\hline
\end{tabular}

(ii) Attraction of new people to green spaces due to the presence of turtles.

We modelled this effect by allowing for a variable efficiency of the general communication related to the presence of turtles. Indeed, it has been repeatedly noted in urban parks in Paris and surroundings that the presence of turtles can attract people who otherwise have no interest in environmental issues or green spaces. This subset of individuals thus increases the subset of urban dwellers potentially receptive to general communication tools.

We supposed that an optimal number of turtles (MeanAtt, see Table 2) could attract people to green spaces who usually do not visit these areas. This number had to be intermediate (here 20 turtles for a 9 ha pond): sufficient to be seen but not so abundant that people avoided ponds due to swarms of turtles. We modelled this effect by correlating the effectiveness of general communication with the number of feral turtles using a Gaussian function ( $m=$ MeanAtt, $\sigma=$ MeanAtt/3). The presence of turtles can enhance the efficiency of the general communication following the efficiency of this attractive effect (see Table 2).

\subsection{Tested scenarios with successful reproduction and sales of turtles}

Finally we examined the four scenarios when reproduction of feral turtles can be successful. For this analysis, we first performed our simulations with all the model parameters fixed and including variable reproductive success (see Table 1 ). We eventually added continuous variable annual turtle sales that annually increase the amount of private owners who can decide, or not, to release their turtle.

\section{Results}

The two considered simulation outputs were: (i) the amount of feral turtles in the managed area across the simulation period and (ii) the rate of people sensitised towards environmental issues across the simulation period. We first compared the four scenarios within each context (from simulations with variable or fixed parameters). Then we compared the results between the two contexts. We finally included variable reproduction and sales of turtles in the model, in the first context where the presence of turtles do not enhance general communication.

For each set of analysis, the results of the four simulated scenarios are plotted together in the same graph; each scenario is represented by a different colour.

\subsection{Dynamics of the amount of feral turtles - no sales of turtles - no successful reproduction}

- Sensitivity analysis: In scenarios 1, 2 and 3, the variability of the results was mainly explained by the releasing process parameters, whereas for the scenario 4, the results were more linked to the efficiency of the general communication. However, the high variability we allowed in all the parameters did not change the relative effectiveness of the scenarios regarding the temporal dynamics of the amount of turtles. When we fixed all parameters but the parameters of the release process and of the communication efficiency, our results did not change.

- Comparison of the four scenarios: The respective spectrums of simulated dynamics when the parameters varied are shown in Fig. 3. The simulated dynamics with fixed parameters are shown in Fig. 4. The differences between the scenarios remained the same regarding the mean trajectories of the amount of turtles in the pond, with or without allowing variability in the parameters. With or without variable parameters, the amount of feral turtles decreased more quickly (2-3 years to reach the plateau) in scenario 1 than in the other three scenarios, regardless of the context (Fig. 4). This number reached a plateau after 3 years in scenario 1 ( $m=4,95 \%$ in $[3.5 ; 5]$ after 20 years), $2(m=5,95 \%$ in $[4.2 ; 6]$ after 20 years) and $3(m=11,95 \%$ in $[9 ; 15]$ after 20 years). Surprisingly however, this parameter continued to decrease all over the simulation period in scenario 4 and reached a lower level ( $m=0.2,95$ in $[0 ; 1]$ after 20 years) than in the three other scenarios, in both contexts. The number of feral turtles reached a lower level in scenario 4 than in scenario 1 (Fig. 4), in both contexts. However, these shifts appeared earlier in the second context (with turtle attraction, fixed parameters, 8 years; Fig. 4b) than in the first context (without any turtle attraction, fixed parameters, 11 years; Fig. 4a).

4.2. Dynamics of the rate of people sensitised to environmental issues and potential damages of introduced species - no sale of turtles - no successful reproduction

- Sensitivity analysis: We tested the model sensitivities only for the scenarios 2, 3 and 4 because in the scenario 1 (i.e., capture only) the environmental awareness did not change over time (linked to the total absence of communication). For the scenarios 2 and 3, the proportion of people environmentally concerned was mostly sensitive to the releasing process parameters, whereas for the scenario 4 , the most sensitive parameter was the efficiency of the general communication. Again, the high variability we allowed in these parameters did not change the relative effectiveness of the scenarios regarding the proportion environmentally concerned people. When we fixed all parameters but the parameters of the release process and of the communication efficiency, the previous results did not change.

- Comparison of the four scenarios: Despite the high variability in the results when allowing variability in the parameters (Fig. 5), the differences between the scenarios remained the same regarding the mean dynamics of the proportion of sensitised people with or without variability in the parameters (Figs. $5,6 a$ and $b)$.

Proportion of people sensitised to environmental issues: the sensitivity of urban dwellers towards conservation issues increased when general communication was performed (scenarios 

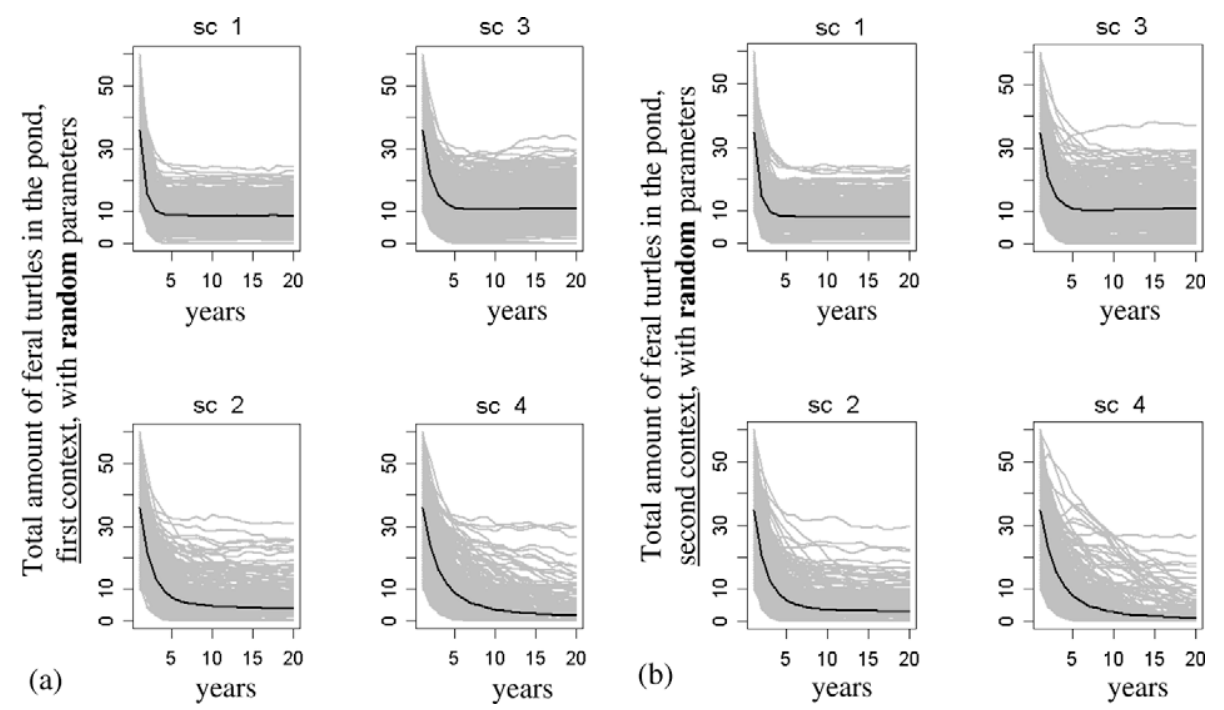

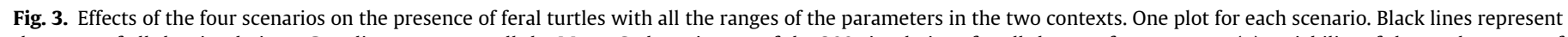

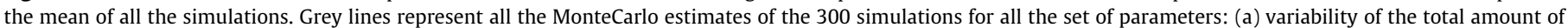

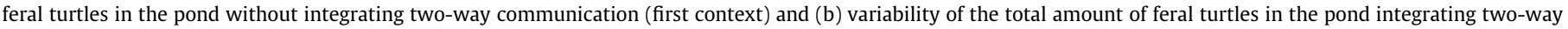
communication (second context).
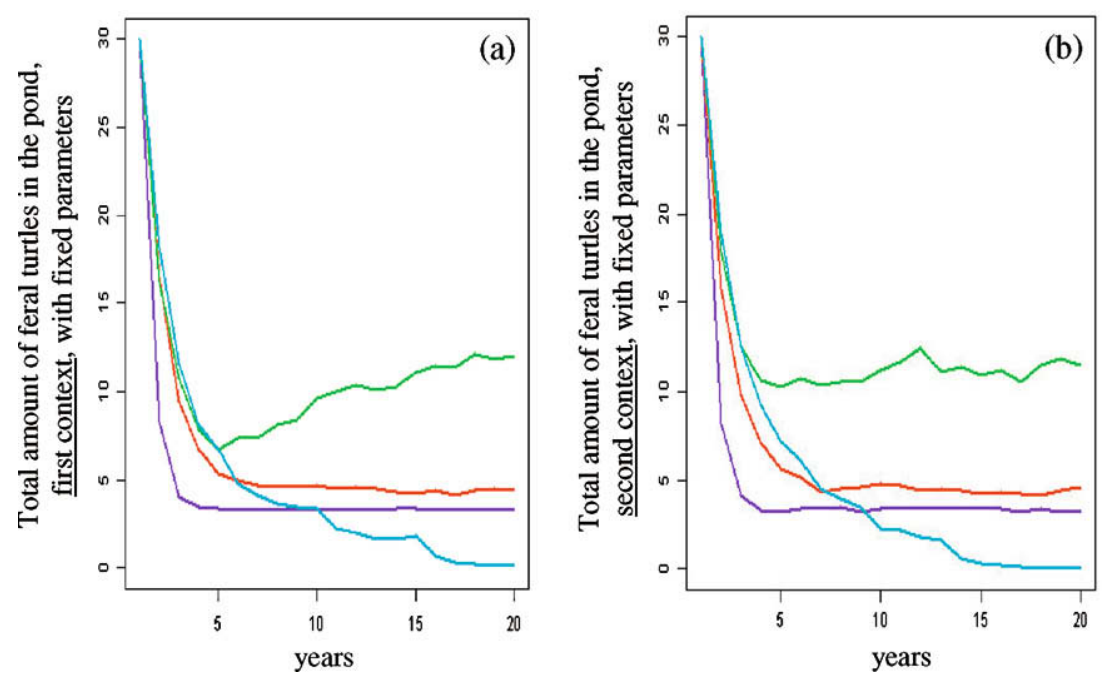

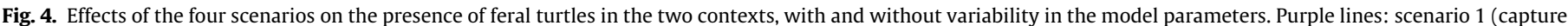

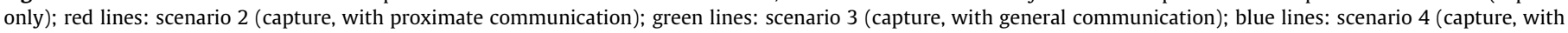

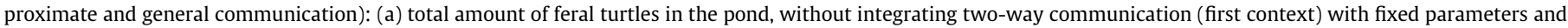
(b) total amount of feral turtles in the pond, integrating two-way communication (second context) fixed parameters.

3 and 4; results not shown), as expected. In scenario 2, as in scenario 1 , the global proportion of people aware of potential damage caused by introduced species remained stable and very low (respectively, $m=0.45,95 \%$ in $[0.35 ; 0.5]$ for scenario 2 and for scenario1 $m=0.25,95 \%$ in $[0.25 ; 0.25]$; Fig. 6$)$. This proportion increased at the population level, but not among the subgroup of people that were environmentally concerned in scenario 3 (capture and general communication) in both contexts (results not shown). scenario 4 was much more efficient $(m=0.95,95 \%$ in $[0.9 ; 0.99]$ after 20 years) at increasing the global proportion of people aware of potential damages caused by introduced species than the others (Fig. 6).

In summary, both manager goals (i.e., reducing the number of feral turtles and increasing the number of urban dwellers concerned about environmental issues) were achieved simultaneously and successfully with scenario 4 (capture, proximate and general communication). In addition, both managers' goals were reached most efficiently in the second context, in which the various perceptions of nature were taken into account, here modelled as the presence of turtles in a green space serving as a motive for the general public to visit green-spaces.

\subsection{Dynamics of the amount of feral turtles - reproduction - continuous sales of turtles}

Integrating turtle reproduction did not change our results on the proportion of urban dwellers sensitised towards environmental issue. However, it changes the dynamics of the amount of feral turtles in the managed area.

In order to study the influence of reproduction on turtle abundance, we fixed all the parameters of the model to the realistic fixed values described in the method section. Indeed, we previ- 


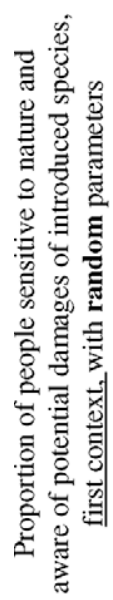

(a)
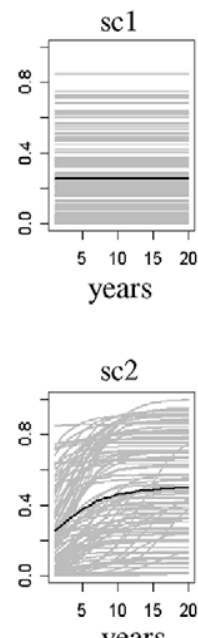

years

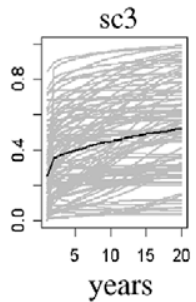

$\mathrm{sc} 4$

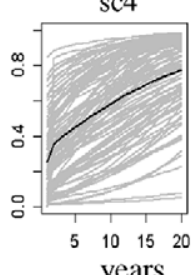

years
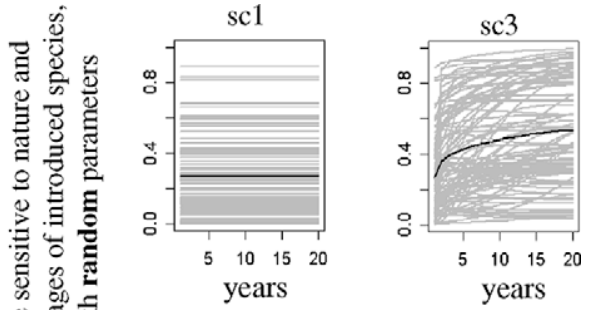

$\operatorname{sc} 2$

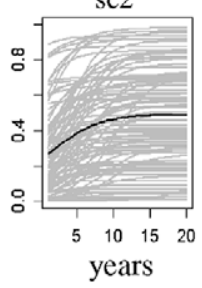

$\operatorname{sc} 4$

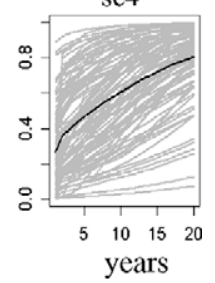

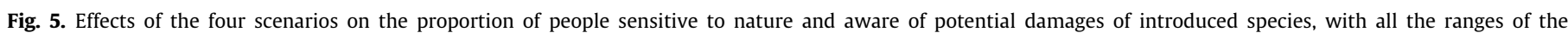

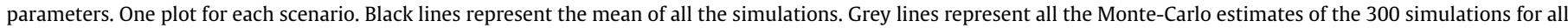

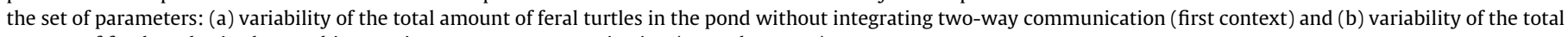
amount of feral turtles in the pond integrating two-way communication (second context).
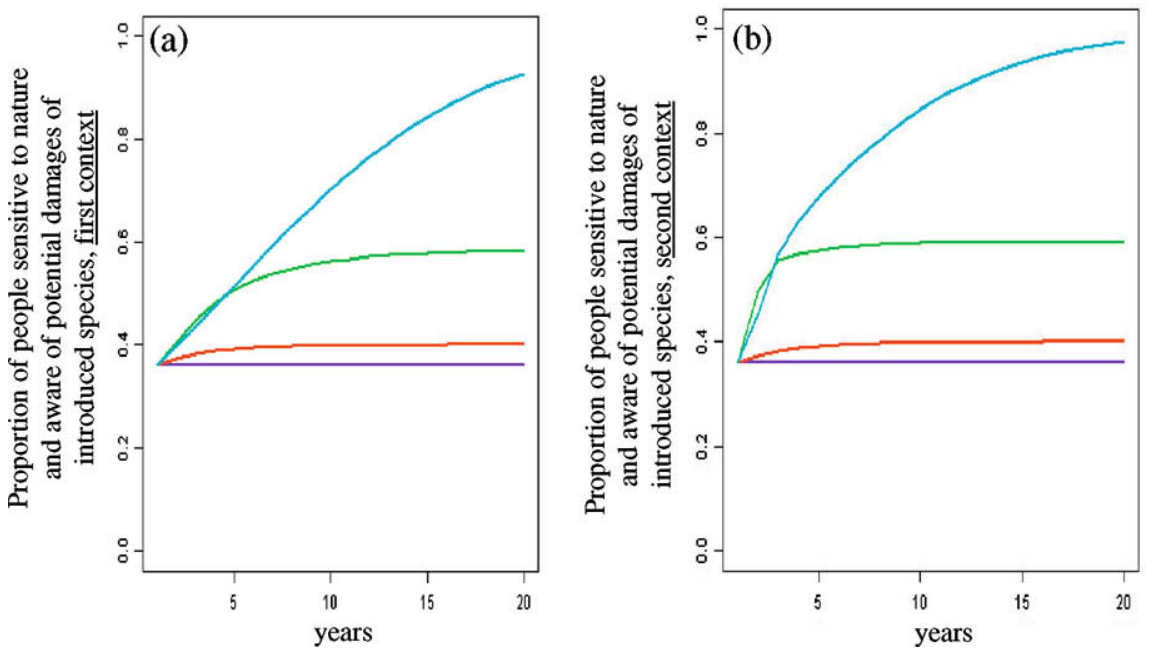

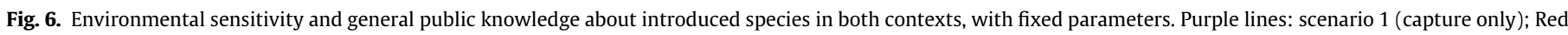

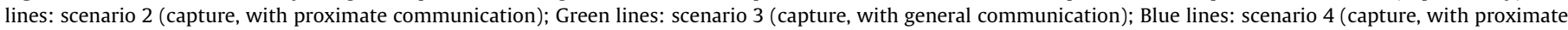

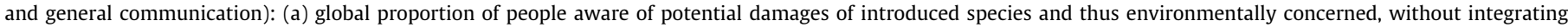

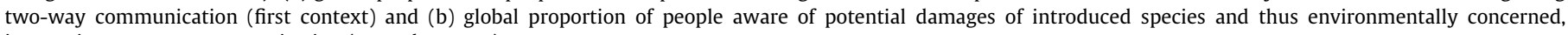
integrating two-way communication (second context).

ously showed that fixing the parameters did not affect our results (see Section 4.1).

Here we only present our results for the simulations with no turtles-attraction effect (first context) but the results are similar in the turtles-attraction (second) context (scenario 4 being even more efficient).

- Successful reproduction of feral turtles, no sales of turtles: except in the scenario 1, the number of feral turtles first increased (for 2-3 years) in all the scenarios (Fig. 7). However, in all the scenarios this amount decreased at a medium time scale (Fig. 7). The amount of feral turtles reached a similar level (data) with or without reproduction, for all scenarios except the scenario 3 (data). However, in the scenario 4, this amount reached a lower value than in all the other scenarios after 10 years, even with successful reproduction. Here again this scenario is the most efficient.
- Successful reproduction of feral turtles, sales of turtles: when there is new turtles sold in addition to successful reproduction, the decrease in numbers was still preceded by an increase for $2-$ 3 first years in the scenarios 2, 3 and 4, whereas there was merely no increase in the scenario 1 (Fig. 8). However, in the scenarios 1, 2 and 3, the amount of turtles only decreased for 5 years and then increased again. It is only in the scenario 4 that the amount of turtles kept decreasing and reached nearly 0 by the end of the 20 years simulations (Fig. 8).

\section{Discussion}

In many cases, managers who face introduced species in their green spaces advocate the precautionary principle of removing every introduced species as soon as it is detected. However, all introduced species do not become invasive. As shown by Shrader-Frechette (2001), there is no predictive "theory of invasibility". 

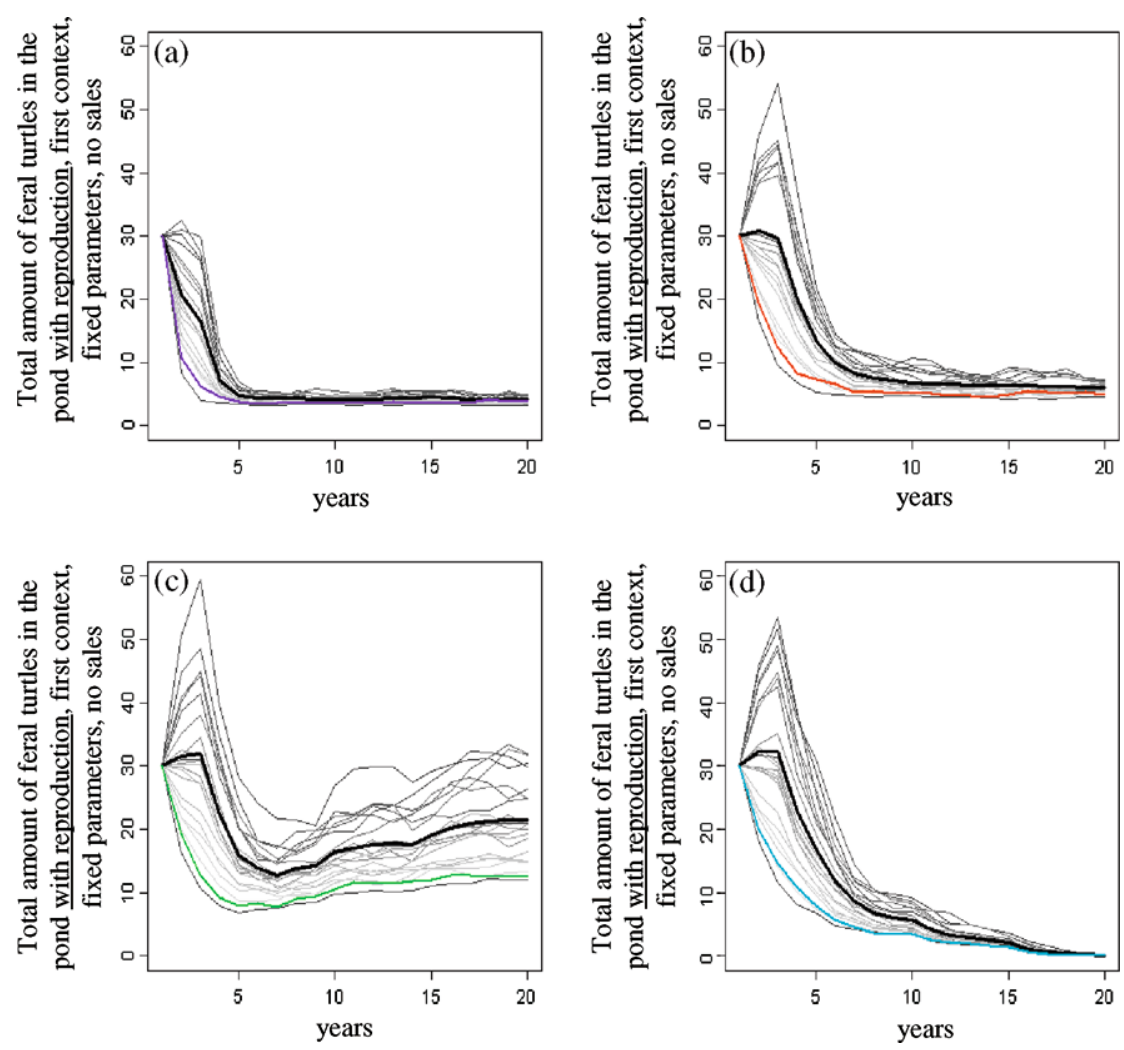

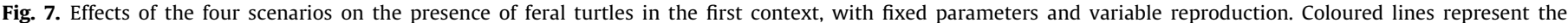

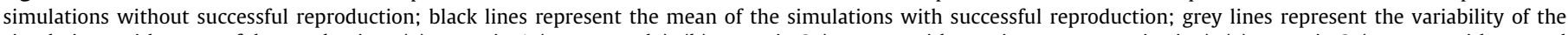

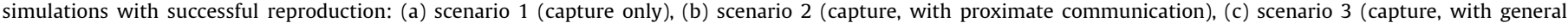
communication) and (d) Blue lines: scenario 4 (capture, with proximate and general communication).

In addition, local conditions are anything but homogeneous and a single solution cannot be relevant everywhere (Sagoff, 2005). In particular, the growing importance of novel ecosystems, such as those created by cities, increases the need to experiment with novel approaches to ecosystem management (Seastedt et al., 2008). Balancing biological data with social and economic considerations - "Pragmatic reconciliation" - is now emerging as the most sustainable solution for preserving global biodiversity (Minteer, 2005).

Here we showed that if managers choose to apply only the precautionary principle, allocating all of their resources to capture only, release events will continue and urban dwellers will not change their behaviour or their concern towards environmental issues. On the other hand, using exclusively communication tools that inform people of the potential damages of introduced species may have only a weak effect in urban areas because their inhabitants do not have pre-existing concerns about their natural environment. The most efficient scenario is one that mixes: (1) capture, which has a short term effect on feral turtle abundance; (2) general communication, which raises awareness towards environmental issues; and (3) proximate communication, which draws attention to the potential threat of introduced species to the environment.

Our results clearly underline the fact that direct actions only (i.e., removing the turtles) have a limited and short term effect (especially true when there is successful reproduction) on feral turtle abundance in green spaces and have no effect on individual awareness or behaviour with respect to introduced exotic pets. In this situation, the direct action must be maintained indefinitely, and thus does not represent a sustainable solution. Quite the contrary, our results clearly demonstrate the need for communication to achieve the complementary management goals of direct biodi- versity preservation and education and to sustain these results over a long time scale. However, the use of only one type of communication approach may induce behaviour opposite to what is intended. For example, where the turtle is perceived as constituting a natural element in the local environment, the number of releases may increase with only general communication, because people think that releasing their turtle is a positive act for nature. The two kinds of communication are obviously complementary. Proximate communication, which is the usual way scientists and managers communicate in conservation, informs the general public about precise and technical conservation issues - in this case, the potential damages caused to the natural environment by feral exotic pets and the injunction against releasing them. However, this message can be received and integrated by potential receivers only if they are already preconditioned to hear and understand the message, such as when receivers and managers share the same concerns about environmental issues. If not, the message can be misunderstood. This kind of technical communication is much more efficient if it is coupled to a communication strategy designed to encourage general concern about environmental and conservation issues - something we have termed general communication. If more people were environmentally concerned, more people would understand and integrate the message delivered by proximate communication. This is why general communication has to be widely disseminated to the public at large using various mental constructions and representations, thereby helping to build the connection between conservationists and people who are not instinctively concerned about the environment. General communication thus complements proximate communication.

The second part of our results shows how important it is to take into account the diversity of people and practices in urban areas. 

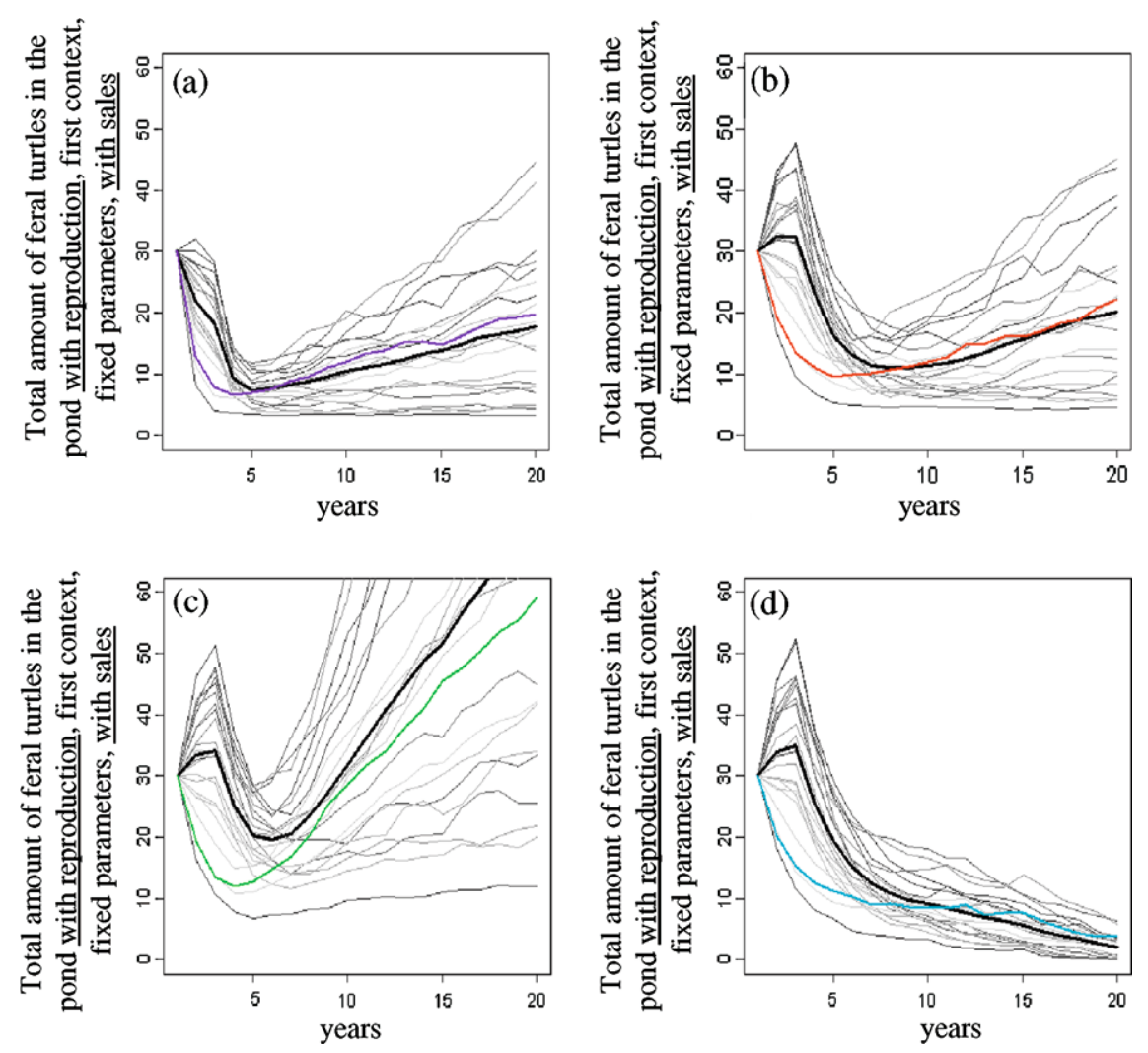

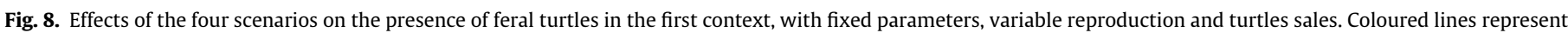

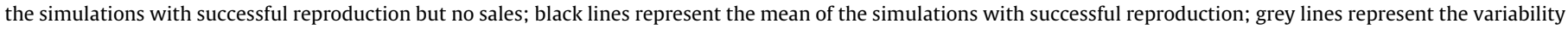

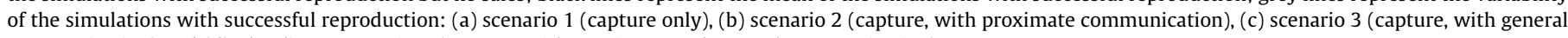
communication) and (d) Blue lines: scenario 4 (capture, with proximate and general communication).

We modelled the different representations thanks to the inclusion of individuals who take pleasure in seeing feral turtles. We postulated that, once attracted to green spaces by the presence of these feral turtles, these people also encounter other facets of nature. As a consequence, they can become receptive to communication (general and/or proximate) concerning the environment and conservation. Taking into account the many perceptions of nature that coexist among people who are, more or less, environmentally concerned provides new avenues of communication between conservationists and the general public.

Our last result underlined the high importance of general and proximate communications to limit the number of feral turtles when people can still buy turtles as pet. Nowadays, most political decisions aim at limiting feral populations of pets discouraging the sales. It may be the easiest solution but encouraging experts to take into account the variability in environmental perceptions and practices might have greater results.

We want to underline that we modelled a simplified situation. First, the simulated area was managed in a constant way by a single manager. Real situations differ from these simulations for at least two main reasons: (i) a given manager can and has to change his management practices regularly (what is not integrated in our model), depending of ecological and social conditions. (ii) It is not a single manager that implements all the communication tools we explored. We have expanded the responsibilities of a manager into arenas typically associated with school teachers or those involved in public policy, especially with respect to general communication responsibilities. The 'manager' category we modelled thus represents a pool of persons that both manage natural areas and communicate with the public using both types of communication.
The dichotomous decision-making process leading to the release of turtles (Fig. 2) is also an over simplification. In reality, the intellectual processes and the emotional considerations that lead to a release decision are much more complex than we have assumed. Our dichotomous description of the releasing process is not a hierarchical process but rather a set of interdependent trade-offs. Moreover, these processes can change according to local situations and personal history. We simplified the human decision-making process so as to implement human behaviours in a simulation model that considered only pre-defined categories.

Based on managers' experience and on authors such as (Brewer, 2002; Dunn et al., 2006; Gobster, 2005; Miller, 2006; Minteer and Collins, 2005a), we assumed that the vast majority of people is not environmentally concerned: they do not integrate biodiversity preservation actively in their everyday life, but most do not even know why and what they should change in their everyday life style according to environmental issues. Many authors assume that people do not preserve environment only because they do not know how important it is for the future. However, this assumption has never been tested in urban areas (Shwartz et al., in preparation). By dividing people in two categories (those who are environmentally concerned and those who are not), we wanted to distinguish people who can be receivers for proximate communication from those who can only be touch by the general communication. And indeed, several managers acknowledged that their education tools (such as field trips, and exhibitions) are followed by people that are already educated. That is why we modelled proximate communication, which aims at delivering information on specific conservation topics to people that want to get this information, and general communication, which aims at opening the general interest of the 
vast majority of people and may become receptive to further proximate communication programs. However, we acknowledged that both general and proximate communication undertake that the behaviour of the receivers (here urban dwellers) will follow the way conservation experts want they follow (i.e., "if they know, they act"). Since we know that such a one-way communication pattern is not relevant for everybody, we tried to model a type of two-way communication process. In such a process, the communication is seen as a relationship between partners, or stakeholders. We modelled the fact that managers can take into account the possible interest of citizens towards feral turtles by giving to a moderate numbers of feral turtles the possibility to increase the efficiency of general communication programs. This positive feeling of urban dwellers towards turtles is the way we chose to model a different perception of nature between experts (managers, scientists) and nonexperts (urban dwellers). We chose this example to illustrate how integrating two-way communication can enhance all environmental measures.

For global conservation efforts to succeed, it is necessary to communicate conservation objectives to the urban public. Moreover, in seeking to re-establish these connections, it is important that communication tools take into account the range of perceptions of nature that exist (see Nespor, 2000; Pandey, 2003). People impact the environment according to how they value it, and this value comprises both economic and non-economic considerations (Martin-Lopez et al., 2007; Stein et al., 1999). The need for a common knowledge is thus desirable because it would allow people to share the way they value their environment. The increasing concentration of people in cities tends to progressively reduce the attention paid to ecological considerations (Miller, 2006; Rosenzweig, 2003). Miller (2006) underlined this phenomenon and urged scientists and managers to attempt to reconnect people with nature. Many authors have recently emphasised an increasing disconnect between urban dwellers and the natural word (e.g., Pyle, 2003). This lack of knowledge leads to both a decreasing interest in conservation (Dunn et al., 2006) and fewer opportunities for future generations to encounter nature (Miller, 2005).

As noted by Lélé and Norgaard (1996), natural scientists should heed lessons from earlier cases where scientists have become involved in policy: the mixing of value judgements and objective facts has important consequences for the direction of research, which in turn, has political implications. Pursuing objective science in a value-loaded and socially charged atmosphere can be accomplished by applying a socially grounded, pluralistic approach to conservation issues.

The responsibility of conservation scientists to consider the larger social background when involved in policy is of growing importance, especially in urban areas where natural environments are intimately linked with human societies. Biological (scientific) arguments must be grounded with a social analysis if sustainable solutions are to be implemented.

One particularly value-loaded question is the presence of feral animal populations in urban areas. A unilateral decision to remove introduced species is not always the best option for preserving biodiversity. Ewel and Putz (2004) concluded that, in restoration, the eradication of alien species is not always cost-effective, showing that certain ecological and socio-economic needs are sometimes better met by alien species than by natives. They also highlighted the fact that the assessment of the risks involved in controlling alien species is likely to be most effective if all stakeholders, not just restoration ecologists, are involved from the start. In urban regions, owning an exotic pet may represent a sort of connection to nature (Digard, 1999). Like other introduced species, feral exotic pets represent a potential threat to local biodiversity.

However, when present in urban areas, feral exotic pets may actually represent an accessible form of nature, one that is easy for the general public to see and appreciate (Minteer and Collins, 2005b). Thus, ironically, the presence of feral exotic pets in the urban landscape may offer a possible way to reconnect people with nature (see Miller, 2006). Based on our findings, we can build on the "positive effects" of released exotic pets in urban green spaces, by noting their reconnection potential. Of course we do not advocate the releasing of exotic pets into wild areas; but we do think it is important to emphasise their role in helping to reconnect city dwellers to environmental issues. We believe that scientists and managers should integrate these different perceptions into the decisions they make to preserve biodiversity (see Dennison et al., 2007; Herrick and Sarukhan, 2007).

In conclusion, we urge scientists to acknowledge the place of personal values and perceptions in environmental issues. We call, as has Minteer and Collins (2005b), for a new integrated and interdisciplinary field of "ecological ethics" that will provide ecological researchers and managers with a critical support network and resource base to improve ethical decision-making. Integrating the various stakeholders' perceptions of nature and conservation issues is a first step towards the respect of these considerations. We bet on respectful behaviours towards human and nature to enhance global conservation concern.

\section{Acknowledgements}

This work is part of collaboration between the laboratory ESE (University Paris-Sud, France) and the Research Unit of Anthropology of Communication (University of Liege, Belgium), founded by CNRS and FNRS/CGRI ( $n^{\circ} 18220$ ).

The "slider turtles" program is funded by the Regional Council of Ile de France, the Direction de l'Environnement Ile de France, the Departemental Councils of Seine-et-Marne, Essonne, Hautsde-Seine and Seine-Saint-Denis.

We thank Joanne Clavel, Alexandre Robert, and Romain Julliard for valuable comments on this manuscript. We also thank Stephen Gregory and Ann Power Smith, from www.writescienceright.com, for language corrections.

\section{References}

Arvy, C., Servan, J., 1998. Imminent competition between Trachemys scripta and Emys orbicularis in France. In: Proceedings of the Emys Sympoisum, Dresden 96, Mertensiella, pp. 33-40.

Bousquet, F., Le Page, C., 2004. Multi-agent simulations and ecosystem management: a review. Ecological Modelling 176, 313-332.

Bremner, A., Park, K., 2007. Public attitudes to the management of invasive nonnative species in Scotland. Biological Conservation 139, 306-314.

Brewer, C., 2002. Outreach and partnership programs for conservation education where endangered species conservation and research occur. Conservation Biology 16, 4-6.

Buijs, A.E., Pedroli, B., Luginbühl, Y., 2006. From hiking through farmland to farming in a leisure landscape: changing social perceptions of the European landscape. Landscape Ecology 21, 375-389.

Cadi, A., Delmas, V., Prévot-Julliard, A.-C., Joly, P., Pieau, C., Girondot, M., 2004. Successful reproduction of the introduced slider turtle (Trachemys scripta elegans) in the south of France. Aquatic Conservation: Marine and Freshwater Ecosystems 14, 237-246.

Chen, T.H., Lue, K.Y., 1998. Ecological notes on feral populations of Trachemys scripta elegans in northern Taiwan. Chelonian Conservation Biology 3, 87-90.

Colding, J., Lundberg, J., Folke, C., 2006. Incorporating green-area user groups in urban ecosystem management. Ambio 35, 237-244.

de Roa, E., Roig, J.M., 1997. Puesta en habitat natural de la tortuga de Florida (Trachemys scripta elegans) en Espana. Boletin de la Asociacion Herpetologica Espanola 8, 48-50.

De'ath, G., Fabricius, K.E., 2000. Classification and regression trees: a powerful yet simple technique for ecological data analysis. Ecology 81, 3178-3192.

Delmas, V., 2006. La tortue à tempes rouges, une espèce exotique et introduite en France: premiers résultats sur les potentialités de colonisation de l'espèce. $\mathrm{PhD}$ thesis, University of Paris-Sud, Orsay.

Dennison, W.C., Lookingbill, T.R., Carruthers, T.J.B., Hawkey, J.M., Carter, S.L., 2007. An eye-opening approach to developing and communications integrated environmental assessments. Frontiers in Ecology and the Environment 5, 307-314.

Digard, J.P., 1999. Les Français et leurs animaux. Fayard, Paris. 
Donlan, J., Greene, H.W., Berger, J., Bock, C.E., Bock, J.H., Burney, D.A., Estes, J.A., Foreman, D., Martin, P.S., Roemer, G.W., Smith, F.A., Soulé, M.E., 2005. Rewilding North America. Nature 436, 913-914.

Dunn, R.R., Gavin, M.C., Sanchez, M.C., Solomon, J.N., 2006. The pigeon paradox: dependence of global conservation on urban nature. Conservation Biology 20, 1814-1816.

Evans, C., Abrams, E., Reitsma, R., Roux, K., Salmonsen, L., Marra, P.P., 2005. The neighborhood nestwatch program: participant outcomes of a citizen-science ecological research project. Conservation Biology 19, 589-594.

Ewel, J.J., Putz, F.E., 2004. A place for alien species in ecosystem restoration. Frontiers in Ecology and the Environment 2, 354-360.

Fischer, A., Young, J.C., 2007. Understanding mental constructs of biodiversity: implications for biodiversity management and conservation. Biological Conservation 136, 271-282.

Gibbons, J.W., 1990. The Life History and Ecology of the Slider Turtle. Smithsonian Institution Press, Washington.

Gobster, P.H., 2005. Invasive species as ecological threat: is restoration an alternative to fear-based resource management? Ecological Restoration 23, 261-270.

Gonzalez del Solar, R., Marone, L., 2001. The "freezing" of science: consequences of the dogmatic teaching of ecology. Bioscience 51, 683-686.

Herrick, J.E., Sarukhan, J., 2007. A strategy for ecology in an era of globalization. Frontiers in Ecology and the Environment 5, 172-181.

Higgs, E., 2006. Restoration goes wild: a reply to Throop and Purdom. Restoration Ecology 14, 500-503.

Jones, H.P., Tershy, B.R., Zavaleta, E.S., Croll, D.A., Keitt, B.S., Finkelstein, M.E., Howald, G.R., 2008. Severity of the effects of invasive rats on seabirds: a global review. Conservation Biology 22, 16-26.

Kaplan, R., Kaplan, S., 1989. The Experience of Nature: A Psychological Perspective. Cambridge University Press, New York.

Kidd, A.H., Kidd, R.M., 1996. Developmental factors leading to positive attitudes toward wildlife and conservation. Applied Animal Behaviour Science 47, 119125.

Lélé, S., Norgaard, R.B., 1996. Sustainability and the scientist's burden. Conservation Biology 10, 354-365.

Lindemann-Matthies, P., 2005. 'Loveable' mammals and 'lifeless' plants: how children's interest in common local organisms can be enhanced through observation of nature. International Journal of Science Education 27, 655-677.

Lonsdale, W.M., 1999. Global patterns of plant invasions and the concept of invasibility. Ecology 80, 1522-1536.

Luiselli, L., Capula, M., Capizzi, D., Filippi, E., Trujillo Jesus, V., Anibaldi, C., 1997. Problems for conservation of pond turtles (Emys orbicularis) in central Italy: is the introduced red-eared turtle (Trachemys scripta) a serious threat? Chelonian Conservation Biology 2, 417-419.

Martinez-Silvestre, A., Soufr-Massana, J., Ventura-Bernardini, M., 2003. Nuevas datos sobre la presencia de reptiles exoticos asilvestrados en la peninsula iberica. Boletin de la Asociacion Herpetologica Espanola 14, 9-11.

Martin-Lopez, B., Montes, C., Benayas, J., 2007. The non-economic motives behind the willingness to pay for biodiversity conservation. Biological Conservation $139,67-82$

McKinney, M.L., 2002. Urbanization, biodiversity, and conservation. Bioscience 52. 883-890.

Miller, J.R., 2005. Biodiversity conservation and the extinction of experience. Trends in Ecology and Evolution 20, 430-434.

Miller, J.R., 2006. Restoration, reconciliation, and reconnecting with nature nearby. Biological Conservation 127, 356-361.

Miller, J.R., Hobbs, R.J., 2002. Conservation where people live and work. Conservation Biology 16, 330-337.

Minteer, B.A., 2005. Environmental philosophy and the public interest: a pragmatic reconciliation. Environmental Values 14, 37-60.

Minteer, B.A., Collins, J.P., 2005a. Ecological ethics: building a new tool kit for ecologists and biodiversity managers. Conservation Biology 19, 1803-1812.

Minteer, B.A., Collins, J.P., 2005b. Why we need an "ecological ethics". Frontiers in Ecology and the Environment 3, 332-337.
Nespor, J., 2000. School field trips and the curriculum of public spaces. Journal of Curriculum Studies 32, 25-43.

Palmer, M.A., Ambrose, R.F., LeRoy Poff, N., 1997. Ecological theory and community restoration ecology. Restoration Ecology 5, 291-300.

Pandey, P.D., 2003. Response to Folke, C., Gunderson, L., 2002. "A kaleidoscope of change" - child participation for conservation of species and ecosystems. Conservation Ecology 7, r(2). <http://www.consecol.org/vol7/iss1/resp2>.

Pascal, M., Lorvelec, O., Vigne, J.D., 2006. Invasions biologiques et extinctions 11000 ans d'histoire des vertébrés en France. Belin, Paris.

Pyle, R.M., 2003. Nature matrix: reconnecting people and nature. Oryx 37, 206-214.

R Development Core Team, 2007. R Reference Manual. Network Theory Ltd.

Rosenzweig, M.L., 2003. Reconciliation ecology and the future of species diversity. Oryx 37, 194-205.

Roskaft, E., Bjerke, T., Kaltenborn, B., Linnell, J.D.C., Andersen, R., 2003. Patterns of self-reported fear towards large carnivores among the Norwegian public Evolution and Human Behavior 24, 184-193.

Ruesch, J., Bateson, G., 1951. Communication: The Social Matrix of Psychiatry. W. W. Norton \& Co. Inc., New York. p. 328.

Sagoff, M., 2005. Do non-native species threaten the natural environment? Journal of Agricultural and Environmental Ethics 18, 215-236.

Sanderson, E.W., Jaiteh, M., Levy, M.A., Redford, K.H., Wannebo, A.V., Woolmer, G., 2002. The human footprint and the last of the wild. Bioscience 52, 891-904.

Sanderson, E.W., Redford, K.H., Weber, B., Aune, K., Baldes, D., Berger, J., Carter, D. Curtin, C., Derr, J., Dobrott, S., Fearn, E., Fleener, C., Forrest, S., Gerlach, C., Gates, C., Gross, J.E., Gogan, P., Grassel, S., Hilty, J.A., Jensen, M., Kunkel, K., Lammers, D., List, R., Minkowski, K., Olson, T., Pague, C., Robertson, P.B., Stephenson, B., 2008. The ecological future of the North American bison: conceiving long-term, largescale conservation of wildlife. Conservation Biology 22, 252-266.

Seastedt, T.R., Hobbs, R.J., Suding, K.N., 2008. Management of novel ecosystems: are novel approaches required? Frontiers in Ecology and the Environment 6, 547553.

Seddon, P.J., Armstrong, D.P., Maloney, R.F., 2007. Combining the fields of reintroduction biology and restoration ecology. Conservation Biology 21, $1388-1390$.

Shannon, C.E., 1948. A mathematical theory of communication. The Bell System Technical Journal 27 (379-423), 623-656.

Shannon, C.E., Weaver, W., 1949. The Mathematical Theory of Communication. University of Illinois Press.

Shrader-Frechette, K., 2001. Non-indigenous species and ecological explanation. Biology and Philosophy 16, 507-519.

Shwartz, A., Turbé, A., Simon, L., Prévot-Julliard, A.C., Julliard, R., in preparation. Conserving urban biodiversity facts versus statements.

Siebert, R., Laschewski, L., Dosch, A., 2008. Knowledge dynamics in valorising local nature. Sociologia Ruralis 48, 223-239.

Simon, S., 2006. Systemic educational approaches to environmental issues: the contribution of ecological art. Systemic Practice and Action Research 19, 143157.

Stein, T.V., Anderson, D.H., Kelly, T., 1999. Using stakeholders' values to apply ecosystem management in an upper Midwest landscape. Environmental Management 24, 399-413.

Stewart, D., 2006. Scottish biodiversity list social criterion: results of a survey of the Scottish population. Research Findings/Environment Social Research, Scottish Executive 26.

Tan, K.W., 2006. A greenway network for Singapore. Landscape and Urban Planning 76, 45-66.

Therneau, T.M., Atkinson, E.J., 1997. An Introduction to Recursive Partitioning using the 13 RPART Routines. Mayo Foundation, Rochester, MN, USA.

Ulrich, R.S., 1984. View through a window may influence recovery from surgery. Science 224, 420-421.

Watzlawick, P., Helmick Beavin, J., Jackson, D.D., 1967. Pragmatics of human communication. A Study of Interactional Patterns, Pathologies and Paradoxes. W.W. Norton \& Co Inc., New York.

Zhao, S., Da, L.J., Tang, Z.Y., Fang, H.J., Song, K., Fang, J.Y., 2006. Ecological consequences of rapid urban expansion: Shanghai, China. Frontiers in Ecology and the Environment 4, 341-346. 